\title{
Pneumatologi Lukas: Karya Roh Kudus dan Implikasinya untuk Orang Percaya Era Postmodern
}

\author{
Anggi Maringan Hasiholan ${ }^{1}$, Daniel Sihotang ${ }^{2}$ \\ Sekolah Tinggi Teologi Bethel Jakarta ${ }^{1,2}$ \\ Korespondensi: anggimaringan.mia2@gmail.com
}

\begin{abstract}
Abstrak: Lukas memberikan porsi tertinggi terkait dengan tema Roh Kudus. Oleh karena itu, pembahasan mengenai pneumatology. Lukas harus diarahkan kepada apa yang sudah, sedang, dan akan dikerjakan atas gereja dan seluruh orang percaya yang adalah tubuh Kristus. Hasil dari karya itu akan berdampak kepada kehidupan jemaat yang bertumbuh secara kualitas dan kuantitas. Namun dewasa ini, Roh Kudus banyak dipandang sebagai kuasa dari luar yang membuat pelayanan seseorang berhasil. Tujuan dari penelitian ini adalah untuk mengungkap kembali karya Roh Kudus dalam hidup orang percaya sebagai pribadi dan tubuh Kristus. Metode penelitian yang digunakan adalah kualitatif deskriptif. Hasil penelitian menunjukkan bahwa pneumatologi Lukas mengarahkan setiap orang percaya masa kini dapat memanifestasikan karya dan kasih Roh Kudus bagi setiap orang. Dengan mengerjakan ini, maka relativitas dunia dalam memahami kasih Tuhan dapat terlihat jelas dalam cara hidup orang percaya yang menjaga harmonisasi seluruh ciptaan.
\end{abstract}

Kata kunci: Lukas, pneumatologi, postmodern

\begin{abstract}
Luke gives the highest portion related to the theme of the Holy Spirit. The Holy Spirit is the person who begins, works, and ends God's work in this world. The results of this work will impact the congregation's life, which grows both in quality and quantity. Nevertheless, the Holy Spirit is widely seen as an external power that makes one's ministry successful. The purpose of this research is to reveal the work of the Holy Spirit in the lives of believers as the person and body of Christ again. The research method used is descriptive qualitative. The results show that Luke's pneumatology directs every believer today to manifest the work and love of the Holy Spirit for everyone. By doing this, the relativity of the world in understanding God's love can see in the way of life of believers who maintain the harmonization of all creation.
\end{abstract}

Keywords: Luke, pneumatology, postmodern 


\section{PENDAHULUAN}

Karunia-karunia roh telah menjadi isu kontroversi yang besar khususnya karena kebangkitan gereja-gereja karismatik utama pada tahun 1960-an dan 1970-an membawa pengalaman dengan karunia-karunia itu melampaui batasan-batasan Pentakosta klasik. ${ }^{1}$ Beberapa tahun terakhir, pengalaman gereja evangelis dan studi Kitab Suci telah menghasilkan minat yang meningkat dan posisi yang berbeda atas pertanyaan, "Apakah semua karunia-karunia Roh Kudus yang disebutkan dalam Perjanjian Baru dapat digunakan di gereja hari ini?" Tanggapan untuk pertanyaan ini telah menghasilkan beberapa pernyataan posisi dan keyakinan yang beragam. Setiap pernyataan keyakinan adalah unik dan beberapa dapat diidentifikasi dengan nama.

Menanggapi pertanyaan ini, muncul dua posisi dasar, yaitu cessationist dan continuousist. Ketika mempertimbangkan karunia-karunia Roh Kudus, kaum cessationist percaya bahwa karuniakarunia tertentu (biasanya yang secara khusus disebutkan dalam 1 Korintus 12:7-11, umumnya diidentifikasi sebagai karunia roh), sudah lama berhenti, ketika para rasul meninggal dan Kitab Suci dikanonkan. Sedangkan continuousist (juga kadang-kadang disebut "non-cessationist") tidak percaya Kitab Suci mendukung sudut pandang ini. ${ }^{2}$ Penulis berpegang pada posisi continuousist, percaya bahwa Tuhan terus menganugerahkan orang percaya dan melakukan tindakan ajaib seperti yang Dia lakukan di Alkitab.

Pembaruan karismatik telah meningkatkan perhatian pada karunia-karunia roh sampai batas tertentu, itu juga mengakibatkan "keasyikan" dengan karunia rohani, yang seharunya fokus kita pada Pemberi hadiah. Kekhawatiran ini

\footnotetext{
1"Karismatik" yang dimaksud adalah mereka yang mendukung dan berusaha mempraktikkan karismata. Istilah ini mencakup umat Kristen dari banyak ragam denominasi dan juga gereja-gereja independen. Untuk studi lebih lanjut lihat Craig S. Keener, Gift and Giver (Grand Rapids: Baker, 2001), p.116

${ }^{2}$ Nicholas Bratcher and Nicholas Bratcher, "Understanding the Mystery: Weighing Cessationist and Continuationist Debate of Prophecy in the Pauline Epistles By" (Western Kentucky University, 2014).
}

telah menghasilkan dua ekstrem. Satu yang terlalu menekankan karunia rohani dan orang yang percaya bahwa karunia tertentu benar-benar berhenti (cessationism). Penulis tidak bergabung dengan salah satu dari pandangan ekstrim ini. Memegang posisi continuousist, penulis menyatakan kebutuhan mutlak akan kedaulatan dan kuasa Roh Kudus di dalam kehidupan sehari-hari orang percaya, serta dalam pelayanan tubuh Kristus, gereja-Nya. Penulis juga merangkul kebenaran bahwa "segala sesuatu telah diciptakan oleh Dia dan untuk Dia". Pemahaman ini mengarahkap orang percaya untuk melakukan segala sesuatu untuk kemuliaan Tuhan. Oleh karena itu, Kuasa Roh, sebagaimana dimanifestasikan dalam karuniakarunia rohani, dianugerahkan terutama untuk memungkinkan orang percaya untuk pelayanan (untuk membangun tubuh Kristus), untuk hidup kudus hidup dan memuliakan Tuhan (Kis. 1:19). ${ }^{3}$ Penulis menyadari bahwa "keasyikan" dengan karunia rohani dapat mengakibatkan dalam penyalahgunaan, pemalsuan dan penyimpangan. Namun, kesalahan dan penyalahgunaan karunia tidak membuat karunia itu sendiri tidak sah. Penyalahgunaan karunia Roh Kudus tidak berarti bahwa kita harus melarang penggunaannya dengan benar.

Topik terkait Roh Kudus tetap mengundang diskusi tajam. Karya Roh Kudus yang dianggap sebagai second blessing bagi orang PentakostaKharismatik tidak dipahami secara esensi. ${ }^{4}$ Itu sebabnya pendalaman terkait dengan karya yang Roh Kudus lakukan perlu dilakukan. Dalam penelitian yang terbuka untuk ditelurusi, dapat dilacak posisi yang mendukung karakter pribadi Roh dalam Lukas, maupun posisi yang dipertahankan yang dipahami Lukas. Roh sebagai kekuatan ilahi impersonal. Jervell yakin bahwa Roh Kudus dalam pekerjaan Lukas adalah kekuatan Tuhan yang impersonal. ${ }^{5}$ Sedangkan François Bovon, yakin bahwa dalam

${ }^{3}$ Christian Reflection, "The Holy Spirit's Gift and Witness" (Pentecost, 2015).

${ }^{4}$ Steven H. Talumewo, Sejarah Gerakan Pentakosta (Yogyakarta: ANDI Offised, 2008).

5acob Jervell, The Theology of the Kisah of the Apostles (New Testament Theology) (Cambridge, MA: Cambridge University Press, 2007). 
Lukas-Kisah Para Rasul Roh Kudus dipahami sebagai pribadi yang nyata. ${ }^{6}$ Ini berarti bahwa setiap kesimpulan teologis akan didasarkan pada analisis tentang tingkat semantik dan naratif. Pertanyaan yang direfleksikan di sini bukanlah apakah dalam Lukas-Kisah Para Rasul Roh Kudus memang seorang pribadi dalam pengertian doktrinal, melainkan analisis secara naratif-biblis.

Penelitian terkait pneumatology Lukas pernah dilakukan oleh Payne yang membahas secara ringkas mengenai janji Bapa akan pencurahan Roh Kudus yang diimplikasikan pada masa kini bagi orang percaya agar tetap percaya pristiwa Bahasa lidah di loteng Yerusalem. ${ }^{7}$ Sedangkan Maccahia membahas baptisan Roh Kudus dan api yang dikaitkan dengan pendamaian yang dilakukan oleh Yesus di atas kayu Salib. ${ }^{8}$ Berdasarkan pemarapan diatas, maka tujuan penelitian ini adalah untuk memberikan suguhan interpretasi pneumatology yang berbeda dari dua penulis diatas sebab diambil dari pemahaman Lukas yang menjadi kekhasan pneumatology bagi teologi Pentakosta.

\section{METODE}

Penelitian ini mengunakan metode kualitatif deskriptif. Pemilihan metode ini agar kajian dari teologi Lukas secara khusus dapat diterapkan kepada pemahaman teologi secara umum. Ciri khas dari teologi Lukas ini dipadukan dalam kehidupan gereja hari ini. Sumber data menggunakan beberapa kepustakaan (library research) yang diambil oleh peneliti. Peneliti pertama-tama melakukan kajian secara komprehensif mengenai pneumatologi dari Lukas. Selanjutnya hasil kajian tersebut diekstrak untuk diarahkan kepada ciri khas pneumatology Lukas yang masih dipegang oleh umat

${ }^{6}$ François Bovon, Luke the Theologian: Fifty-Five Years of Research (1950-2005) (Waco, Tex: Baylor University Press, 2007).

${ }^{7}$ John Mayne, "Pneumatology in Lukes Gospel" (Malyon College, 2013).

${ }^{8}$ Frank D. Macchia, "Baptism in the Holy Spiritand-Fire: Luke's Implicitly Pneumatological Theory of Atonement," Religions 9, no. 2 (2018), https://doi.org/10.3390/rel9020063.
Pentakosta. Selanjutnya hasil ekstraksi dipakai untuk menilai corak berpikir orang percaya postmodern ini yang erat kaitannya dengan pluralism dan relativisme.

\section{PEMBAHASAN}

\section{Roh Kudus dalam Perspektif Lukas}

Roh Kudus dalam Injil Lukas yang ia sebut sebagai bagian-bagian dalam Kisah Para Rasul ${ }^{9}$ adalah memoar penulis Lukas-Kisah Para Rasul, yang secara tradisional diidentifikasi sebagai Lukas, atau buku harian perjalanan yang sebelumnya disimpan oleh salah satu rekanrekan Paulus, mungkin Silas atau Timotius, yang kemudian dimasukkan oleh editor tak dikenal ke dalam catatannya. ${ }^{10}$ Jika mereka adalah yang pertama, dan ini adalah penjelasan yang paling alami, maka Lukas penulis dan kadang-kadang rekan Paulus, secara pribadi berpartisipasi dalam perjalanan misionaris Paulus. Oleh karena itu, ketika dia datang untuk menulis kisah misi ini, Lukas tidak hanya dapat berkonsultasi dengan peserta lain, tetapi dia juga dapat mengambil dari pengalamannya sendiri. Namun, untuk menulis sejarah lengkap misi ini, ia harus mulai dengan asal mula kesaksian kerasulan ini, yaitu karunia Roh Kudus kepada para murid pada hari Pentakosta. Selain itu, untuk menjelaskan Pentakosta, ia tentu harus mengawali kisah Yesus, Injil ke kisah kesaksian kerasulan ini.

Partisipasi Lukas dalam misi Paulus kepada orang-orang bukan Yahudi sebagian menjelaskan transformasi genre Injil dari "injil" Markus menjadi "sejarah keselamatannya." Ketika ia mereduksi kisah Yesus menjadi tulisan, Markus, karena kebutuhan, mengembangkan literatur Kristen yang unik ini. ${ }^{11}$ Injil menurut Markus bukanlah sejarah atau biografi; menurut tradisi gereja mula-mula, itu adalah catatan tertulis tentang khotbah Petrus di Roma. Menurut

${ }^{9}$ Bagian "kita" adalah Kisah Para Rasul 16:10-17; 20:5-21:18; 27:1-28:16

${ }^{10}$ L. Howarld Marshal, Luke: Historian and Theologian (Grand Rapids, MI: Zondervan Publishing, 1998).

${ }^{11}$ Ralph P. Martin, New Testament Foundations: A Guide for Christian Students (Grand Rapids: Eerdmans, 2016). 
konsensus ilmiah, Injil Markus adalah sumber utama yang mendasari Injil Lukas. Namun, dengan menambahkan narasi kelahiran, memperluas narasi pelantikan, dan kemudian menetapkan keseluruhan cerita ke dalam kerangka kronologis dan geografis Yudaisme di bawah kekaisaran Roma, Lukas secara radikal mengubah "injil" Markus, sehingga menciptakan "sejarah keselamatan" Kristen sebagai lanjutan dari sejarah suci Israel.

Lukas menaruh perhatian tentang Roh Kudus dalam porsi yang cukup banyak di dalam kitabnya, yakni lima belas kali dalam Injil Lukas dan lima puluh lima kali dalam Kisah Para Rasul. Jumlah ini jauh lebih banyak dibandingkan dengan Injil Markus yang hanya menyebut enam kali, dan Injil Matius yang hanya dua belas kali. Data ini menyimpulkan bahwa Roh Kudus adalah tema kunci Lukas. Jelas juga bahwa Lukas melakukannya tidak bergantung pada dua sinoptik lainnya untuk pneumatologinya. Bahkan dalam beberapa kesempatan, Lukas "mengimpor" Roh Kudus di mana Markus dan Matius tidak menyebutkannya. ${ }^{12}$ Ketertarikan ini terlihat dalam tabel yang disusun oleh Moore $^{13}$ sebagai berikut:

\begin{tabular}{|l|l|l|}
\hline Text & $\begin{array}{l}\text { Pribadi yang } \\
\text { Dipenuhi Roh }\end{array}$ & $\begin{array}{l}\text { Pemberdayaan } \\
\text { untuk Melibatkan } \\
\text { dalam Persekutuan }\end{array}$ \\
\hline Luk. 1:15 & $\begin{array}{l}\text { Yohanes } \\
\text { Pembaptis }\end{array}$ & $\begin{array}{l}\text { Mempersiapkan } \\
\text { jalan untuk Yesus }\end{array}$ \\
\hline Luk. 1:35 & Maria & $\begin{array}{l}\text { Pemahaman akan } \\
\text { Mesias }\end{array}$ \\
\hline Luk. 1:41 & Elisabeth & $\begin{array}{l}\text { Mengumumkan } \\
\text { Yesus dalam rahim } \\
\text { Maria }\end{array}$ \\
\hline Luk. 1:67 & Zakharia & $\begin{array}{l}\text { Nubuat tentang } \\
\text { Yohanes Pembaptis }\end{array}$ \\
\hline Luk. 2:25-27 & Nabi Simeon & $\begin{array}{l}\text { Mengenali } \\
\text { kedatangan Yesus }\end{array}$ \\
\hline Luk. 3:22; 4:1 & Tuhan Yesus & $\begin{array}{l}\text { Membawa kepada } \\
\text { godaan Iblis di } \\
\text { padang gurun }\end{array}$ \\
\hline Luk. 4:14, 18 & Tuhan Yesus & Berkhotbah \\
\hline Luk. 10:21 & Tuhan Yesus & Khotbah dengan \\
\hline
\end{tabular}

${ }^{12}$ F. F. Bruce, "The Holy Spirit in the Kisah of the Apostles," Interpretation: A Journal of Bible and Theology 27, no. 2 (1973): 166-183.

${ }^{13}$ Mark Moore, "Luke's View of the Holy Spirit," Enrichment Journal, 2018.

\begin{tabular}{|c|c|c|}
\hline & & sukacita \\
\hline Luk. 12:12 & Murid-murid & $\begin{array}{l}\text { Menginjil dengan } \\
\text { berani }\end{array}$ \\
\hline Kis. $1: 2$ & Tuhan Yesus & $\begin{array}{l}\text { Mengajarkan para } \\
\text { rasul }\end{array}$ \\
\hline Kis. 1:8 & Para Rasul & Menginjili dunia \\
\hline Kis. $1: 16$ & Daud & Menulis kitab \\
\hline Kis. 2:4, 33 & Para Rasul & Berbahasa lidah \\
\hline Kis. 2:17-18 & $\begin{array}{l}\text { Seluruh orang di } \\
\text { loteng Yerusalem }\end{array}$ & Nubuat \\
\hline Kis. $4: 8$ & Petrus & $\begin{array}{l}\text { Bersaksi dihadapan } \\
\text { Sanhendrin }\end{array}$ \\
\hline Kis. $4: 25$ & Daud & Menulis Kitab Suci \\
\hline Kis. 4:31 & Gereja & $\begin{array}{l}\text { Berbicara dengan } \\
\text { berani }\end{array}$ \\
\hline Kis. 6:10 & Stefanus & $\begin{array}{l}\text { Berbicara dengan } \\
\text { berani }\end{array}$ \\
\hline Kis. $8: 29$ & Filipus & $\begin{array}{l}\text { Diarahkan ke } \\
\text { Etiopia }\end{array}$ \\
\hline Kis. 8:39 & Filipus & $\begin{array}{l}\text { Dipindahkan ke } \\
\text { Azotus }\end{array}$ \\
\hline Kis. 9:31 & Gereja Tuhan & $\begin{array}{l}\text { Mengalami } \\
\text { pertumbuhan }\end{array}$ \\
\hline $\begin{array}{l}\text { Kis. 10:19; } \\
11: 12\end{array}$ & Petrus & $\begin{array}{l}\text { Diarahkan untuk } \\
\text { pergi bersama } \\
\text { pelayan Kornelius }\end{array}$ \\
\hline Kis. $10: 38$ & Tuhan Yesus & Melakukan mujizat \\
\hline $\begin{array}{l}\text { Kis. 10:44-47; } \\
11: 15-16 ; 15: 8\end{array}$ & $\begin{array}{l}\text { Keluarga } \\
\text { Kornelius }\end{array}$ & $\begin{array}{l}\text { Berbicara dengan } \\
\text { bahasa lidah }\end{array}$ \\
\hline $\begin{array}{l}\text { Kis. 11:28; } \\
21: 11\end{array}$ & Agabus & Nubuat \\
\hline Kis. 13:2-4 & $\begin{array}{l}\text { Paulus dan } \\
\text { Barnabas }\end{array}$ & $\begin{array}{l}\text { Pergi dalam misi } \\
\text { pertama }\end{array}$ \\
\hline Kis. $13: 9$ & $\begin{array}{l}\text { Paulus dan } \\
\text { Barnabas }\end{array}$ & Menegur Elimas \\
\hline Kis. $15: 28$ & Yudas dan Silas & $\begin{array}{l}\text { Menulis keputusan } \\
\text { kepada orang non } \\
\text { Yahudi }\end{array}$ \\
\hline Kis. $16: 6-7$ & Paulus dan Silas & $\begin{array}{l}\text { Dihalangi oleh Roh } \\
\text { Kudus dan dipaksa } \\
\text { masuk Makedonia }\end{array}$ \\
\hline Kis. $19: 2,6$ & Murid di Efesus & $\begin{array}{l}\text { Bernubuat dan } \\
\text { berbicara dalam } \\
\text { bahasa lidah }\end{array}$ \\
\hline Kis. 20:22-23 & Paulus & $\begin{array}{l}\text { Dipaksa untuk } \\
\text { melakukan } \\
\text { perjalanan ke } \\
\text { Yerusalem } \\
\end{array}$ \\
\hline Kis. 20:28 & Para Penatua & Menjadi penatua \\
\hline Kis. 21:4 & Saudara-saudara & Menasihati Paulus \\
\hline Kis. 28:25 & Yesaya & Menulis Kitab Suci \\
\hline
\end{tabular}

Lukas menyebutkan bahwa Roh Kudus adalah pembimbing, pelindung, dan penolong bagi seluruh orang percaya, terutama tubuh Kristus. Lukas secara massif menjelaskan 
peranan Roh Kudus agar pembacanya menyadari bahwa sumber pergerakan dinamis yang menyebabkan orang percaya melakukan firman Tuhan adalah Roh Kudus. Roh inilah yang dimiliki oleh murid-murid Yesus. Dia ingin setiap pembaca mengetahui bagaimana orang biasa seperti para murid Yesus dapat menjadi orang yang melakukan keberanian, pengertian dan kemampuan yang melebihi rata-rata. ${ }^{14}$ Yang membedakan Kekristenan dengan kepercayaan lain adalah tawaran kekuatan yang dinamis yang dibutuhkan supaya dapat hidup serupa seperti Yesus hidup. Inilah kekuatan dari Roh Kudus yang disebut juga "Roh Yesus" (Kis. 16:7). Kekuatan ini merupakan penyertaan Yesus kepada mereka di dalam cara baru dan penuh kuasa.

Roh Kudus juga dikaitkan erat dengan baptisan Roh Kudus. Ini diidentifikasi dua kali dalam kitab Kisah Para Rasul (2:1-4; 10:44-46; 11:16). Di sini ditemukan para Rasul (lih. Kis 1:26; 2:1, 5, 7, 14, 37) dan keluarga Kornelius berbicara dalam bahasa roh sebagai bukti persetujuan Allah. Pada hari Pentakosta, Allah mengukuhkan para Rasul sebagai juru bicara dan saksi kebangkitan. Di rumah Kornelius, Tuhan memvalidasi orang bukan Yahudi pertama sebagai prospek yang bonafid untuk konversi. Dalam kedua kasus itu, baptisan Roh Kudus tidak sama atau tidak perlu untuk keselamatan. Para Rasul sudah diselamatkan dan Kornelius mulai dibaptis dalam air sesuai dengan praktik pertobatan Kristen abad ke-1 yang normal. Intinya: Hanya dua kali dalam Perjanjian Baru yang mengidentifikasi baptisan Roh Kudus, itu bukan untuk keselamatan tetapi validasi.

\section{Peran Roh Kudus dalam Perspektif Lukas}

Berbicara tentang peran Roh Kudus, maka aturan utamanya adalah bahwa Roh Kudus melakukan apa yang Dia inginkan, di mana Dia mau, kapan Dia mau, dan bagaimana Dia mau, dengan atau tanpa izin manusia atau para murid Yesus. Dia sangat kreatif dan tidak dapat diprediksi secara bawaan dan terlalu besar untuk

${ }^{14}$ Alger Fitch, KISAH: What a Doctor Found When He Examined Christ's Body, 2nd ed. (Surabaya: YAKIN, 2011). "kotak teologis" mana pun yang mungkin kita bangun. Faktanya, Roh Kudus cenderung klaustrofobia. Jadi, dengan berbicara tentang perannya, kita tidak memprediksi (atau membatasi) apa yang akan dia lakukan, tetapi menelusuri apa yang telah Dia lakukan.

\section{Roh Kudus Memberdayakan Umat Tuhan untuk Pelayanan}

Kisah Para Rasul 1:8 secara eksplisit menyatakan bahwa "Tetapi kamu akan menerima kuasa, kalau Roh Kudus turun ke atas kamu; dan kamu akan menjadi saksi-Ku di Yerusalem dan di seluruh Yudea dan Samaria dan sampai ke ujung bumi." Ini berdiri tepat di atas bahu paradigma yang sudah ditetapkan dalam Lukas 1:35 mengatakan, "Roh Kudus akan turun ke atas kamu, dan kuasa Yang Mahatinggi akan menaungi kamu. ${ }^{15}$ Menariknya, Lukas adalah satu-satunya penulis Injil yang mencatat bahwa Yesus diberdayakan oleh Roh Kudus untuk melakukan pekerjaan yang dahsyat (Luk. 4:1, 14, 18; 10:21; 24:19; Kis 1:2; 2:22; 10:38), khususnya menonjol dalam pembaptisan, pencobaan, dan khotbah pertamanya di Nazaret. Stronstad berpendapat bahwa dalam struktur Lukas-Kisah Para Rasul, narasi Pentakosta berdiri dalam hubungan yang sama dengan Kisah Para Rasul seperti halnya narasi-narasi masa kanak-kanak-peresmian dalam Injil. Dalam Injil Lukas, narasi-narasi ini tidak hanya memperkenalkan motif-motif yang mendefinisikan misi Yesus, tetapi juga menunjukkan bahwa Yesus akan melaksanakan misi-Nya dalam kuasa Roh Kudus. Dengan cara yang sama, narasi Pentakosta memperkenalkan misi masa depan para murid dan pemberdayaan Roh yang saling melengkapi. ${ }^{16}$

Hubungan erat antara karunia Roh dan kuasa ini, seperti yang telah kita lihat, juga mencirikan periode Injil. Ini benar untuk Maria

\footnotetext{
${ }^{15}$ Sarah Andriati, "Pemahaman Tentang Karunia
} Roh Kudus Dalam Pemberdayaan Kualitas Guru Pendidikan Agama Kristen," Jurnal Antusias 4, no. 7 (2018): 34-61.

${ }^{16}$ Roger Stronstad, The Charismatic Theology of St. Luke: Trajectories from the Old Testament to Luke-Kisah, 2nd ed. (Grand Rapids: Baker Publishing, 2012). 
yang dikandung Yesus (Luk. 1:35), Yohanes Pembaptis (1:17), dan, yang paling penting, untuk Yesus (4:14). Janji kuasa sebagai manifestasi Roh meyakinkan para murid bahwa Yesus tidak akan meninggalkan mereka pada sumber daya mereka sendiri. Sebaliknya, mereka akan diperlengkapi sepenuhnya untuk tugas mereka sebagai saksi (Kis. 4:33). Memang, mereka akan menerima kuasa yang sama dengan yang Yesus lakukan dalam pelayanannya di bumi. Oleh karena itu, sebagaimana misi Yesus diresmikan dalam kuasa Roh, demikian pula pada Pentakosta misi para murid akan diresmikan dalam kuasa Roh.

Pertanyaannya kemudian menjadi, "Kekuatan untuk apa?" Apa yang memungkinkan Roh Kudus untuk dilakukan para murid? Jawabanannya sederhana, "Apa pun yang diperlukan untuk mempromosikan Yesus.” Jelas itu termasuk mukjizat, seperti penyembuhan (Kis. 2:43; 3:6-7; 5:12, 15-16; 6:8; 8:6-8; 9:18, 34, $40 ; 10: 38 ; 14: 3,8 ; 19: 11-12 ; 20: 10 ; 28: 8-9)$, pengusiran setan (Kis. 5:16; 16:18), pelarian ilahi (Kisah 5:19; 12:7; 27:23-26), bahkan hukuman (Kis. 5:5, 9; 8:20; 13:11). Demikian dalam berkhotbah yang dapat mengambil beberapa bentuk: Bahasa lidah (Kis. 2:1-4; 10:45-46; 19:6); Nubuat (Luk 21:20-24; Kis. 11:28; 21:11); khotbah yang berani (Luk. 4:18; 6:10; 12:12; Kis. $4: 8 ; 13: 9)$, pernyataan yang menggembirakan (Luk 2:25-27; 10:21), surat-surat doktrinal (Kis. 15:23-29), bahkan ucapan puitis (Luk. 1:46-55, 67-79). Semua ini dilakukan oleh wanita dan pria, tua dan muda, Yahudi dan Yunani, Rasul, diaken, imam, nabi, pengkhotbah, dan awam. Sungguh Roh Kudus menggunakan kreativitas dan keragaman terbesarnya untuk memberitakan kabar baik Yesus. ${ }^{17}$ Drewes mengungkapkan bahwa baptisan Roh Kudus dipandang sebagai tanda pengakhiran zaman dunia ini (Kis. 2:17 dikatakan bahwa "akan terjadi pada hari-hari terakhir..."). ${ }^{18}$

\footnotetext{
${ }^{17}$ Moore, "Luke's View of the Holy Spirit."

${ }^{18}$ B.F. Drewes, Tafsiran Alkitab: Kisah Para Rasul (Jakarta: BPK Gunung Mulia, 2014).
}

Roh Kudus Menggerakkan Penginjilan

Ketika Lukas berbicara tentang Roh Kudus, dia menggambarkan perannya sebagai salah satu pemberdayaan bagi saksi. ${ }^{19}$ Penyebutan Roh Kudus pertama-tama dalam Kisah Para Rasul merupakan kelanjutan dari persiapan muridmurid untuk melaksanakan Amanat Agung. Prinsip ini penting untuk dipahami oleh pembacanya. Lukas (khususnya Kisah Para Rasul) tidak sedang menjelaskan mengenai Roh Kudus. Menurut Wehman Lukas tidak sedang menulis kitab tentang Roh Kudus, dia sedang menulis kitab tentang penyebaran Injil, dan dia ingin menggambarkan peran sentral Roh Kudus dalam pekerjaan itu. ${ }^{20}$ Senada demikian, Marshal menegaskan bahwa di dalam kesaksian Roh Kudus memiliki peran utama, Roh Kudus bukanlah tema dalam tulisan Lukas. ${ }^{21}$ Seorang saksi dapat berperan dalam dewan pengadilan di mana ada pro dan kontra (Luk. 22:71; Kis. 6:13). Setiap inisiatif dalam penginjilan yang dicatat dalam Kisah Para Rasul adalah inisiatif dari Roh Kudus. ${ }^{22}$ Akan tetapi, diluar pengadilan juga saksi dapat muncul dan memberi keterangan mengenai kebenaran.

Lukas menggambarkan Roh Kudus sebagai pengajar daripada bahan pengajaran. Tetap Yesus sebagai tema khotbah yang disampaikan oleh para murid. Roh Kudus yang membawa Filipus untuk bertemu dengan Sida-sida dari Etiopia tidak menjadi topik pembicaraan kedua orang pada saat itu (Kis. 8). Pembicaraan mereka adalah untuk memberitakan Injil Kristus (Kis. 8:35). Dalam King James Version dituliskan secara eksplisit bahwa Filipus "berkhotbah tentang Yesus." Demikian bahwa khotbah tentang Injil yang pertama adalah tentang "Yesus dari Nazaret" (Kis. 2:22) dari awal mula sampai akhir. Petrus juga menyimpulkan bahwa "Allah telah

\footnotetext{
${ }^{19}$ James Sheldon, Mighty in Word $\mathcal{E}$ Deed: The Role of the Holy Spirit in Luke-Kisah (Peabody, Massachusetts: Hendrickson Publishers, Inc, 2000).

${ }^{20}$ G. J. Wenham et al., New Bible Commentary (Downers Grove, IL: InterVarsity Press, 1994).

${ }^{21}$ I Howard Marshall, Luke: Historian and Theologian (Downers Grove: InterVarsity Press, 1998).

${ }^{22}$ Michael Green, Evangelism in the Early Church, Revised (Grand Rapids: Eerdmans Publishing Co - A, 2004).
} 
membuat Yesus ... menjadi Tuhan dan Kristus.” Drewes menegaskan bahwa Kuasa dari Roh Kudus ditujukan agar orang percaya menjadi saksi Kristus, khususnya mengenai kebangkitanNya (Luk. 1:21-26; 2:32; 3:15; 5:32; 10:41; 13:31). ${ }^{23}$ Demikian dengan Moore yang menggunakan data table di atas menekankan bahwa $76 \%$ dari waktu Roh turun ke atas seseorang, Dia memberdayakan mereka untuk berbicara sebagai lawan dari beberapa pelayanan atau tugas lainnya. Jelas, apa yang paling diperhatikan Roh adalah secara lisan mempromosikan Yesus Kristus sebagai penyelamat dunia. Oleh karena itu, untuk benarbenar dipenuhi Roh, paling jelas ditunjukkan melalui khotbah, pengajaran, dan penginjilan. ${ }^{24}$ Bahkan Gunkel berpendapat bahwa gereja mulamula tidak tertarik pada teologi Roh Kudus (pernyataan kredo) tetapi pada tindakan konkretnya. ${ }^{25}$

Roh Kudus tidak hanya memberdayakan umatnya untuk berbicara tetapi dia juga membuat "koreografi" gerakan mereka. Simeon, di antara sekitar 19.000 imam lainnya pergi ke tempat yang tepat di halaman bait suci, kira-kira seukuran 16 lapangan sepak bola (Luk 2:25-27) dan Anna bergabung dengannya (Luk 2:38). Yesus dibawa oleh Roh ke padang gurun (Luk 4:1). Filipus dibawa ke tempat yang tepat di jalan yang sepi pada waktu yang tepat untuk bertemu dengan Kasim Etiopia (Kis. 8:29), dan "dirampas" ke Azotus (Kis. 8:39). Ananias diberi alamat jalan tempat bertemu Saulus (Kis. 9:11); Peter, tepatnya di waktu yang tepat, disuruh pergi dengan tiga utusan dari Kornelius (Kis. 10:17-20; 11:12). Paulus dan Barnabas diutus dalam perjalanan misi pertama mereka (Kis. 13:2), dan kemudian Paulus secara khusus dibawa ke Makedonia (Kis. 16:6-10) dan Yerusalem (Kis. 20:22). ${ }^{26}$ Penginjilan adalah

\footnotetext{
${ }^{23}$ Drewes, Tafsiran Alkitab: Kisah Para Rasul.

${ }^{24}$ Moore, "Luke's View of the Holy Spirit."

${ }^{25}$ Hermann Gunkel, The Influence of the Holy Spirit,
} ed. Tr. Roy A. Harrisville and Philip A Quanbeck (Philadelphia: Fortress Press, 1979).

${ }^{26}$ Friedrich Baumgärtel, Theological Dictionary of the New Testament, ed. Gerhard Kittel, Gerhard Friedrich, and Geoffrey Bromily (Grand Rapids, MI: Eerdmans, 2012). tugas orang percaya, tetapi jelas itu adalah misi Roh Kudus.

Roh Kudus tidak hanya mengatur pertemuan, namun, Dia menyegel kesepakatan (2 Kor 1:22; 5:5; Ef 1:13). Memang Rasul Pauluslah yang paling banyak berbicara tentang peran Roh dalam pertobatan (Rm. 2:29; 8:9; Gal 3:14; Tit. 3:5). Sheldon dengan tepat memperingatkan kita, "Meskipun Lukas tidak menolak untuk menghubungkan Roh Kudus dengan pertobatan, ini bukanlah dorongan pneumatologis utamanya." ${ }^{27}$ Meskipun demikian, Roh masih berhubungan dengan pertobatan dalam Kisah Para Rasul. Secara khusus, ia dikaitkan dengan baptisan air (Kis. $2: 38-39 ; 9: 17-22 ; 19: 2-5$, dengan pengecualian 8:15-18).

Roh Kudus Mendukung dan Mendorong Gereja

Roh Kudus adalah pecinta kemanusiaan. Tujuan-Nya bukan hanya untuk membawa orang percaya ke dalam hubungan yang benar dengan Allah, tetapi untuk membangun kita, menopang, dan mendorong kita melalui tubuh Kristus. Ini memanifestasikan dirinya setidaknya dalam dua cara spesifik dalam literatur Lukas: sukacita dan doa. Lukas pasti memiliki kecenderungan yang "periang." Dia sering menyebutkan sukacita (Luk $1: 14,28,44,47,58 ; 2: 10 ; 6: 23 ; 10: 17-21 ; 15: 7$ $10 ; 19: 6,37-40 ; 24: 41,52$; Kis 3:8-9; 5:41; 8:8, 39; $14: 17$; 16:34). Dalam beberapa kesempatan kegembiraan secara khusus dikaitkan dengan Roh (Luk 1:41, 46, 67; 10:21; Kis 11:23-24; 13:52),32 terutama Lukas 10:21, "Pada waktu itu Yesus, penuh sukacita melalui Roh Kudus, kata . .." dan Kisah Para Rasul 13:52, "Maka penuhlah murid-murid itu dengan sukacita dan oleh Roh Kudus." Sementara tujuan akhir-Nya lebih besar daripada kepuasan pribadi kita, karena kasih-Nya yang besar, Ia akan menerima tidak kurang dari kesehatan lengkap tubuh Kristus, yang mencakup sukacita atas pekerjaan besar Allah di dalam kita.

Lukas juga menekankan hubungan Roh dengan doa. Montague berkata, "Yang paling

${ }^{27}$ Sheldon, Mighty in Word 83 Deed: The Role of the Holy Spirit in Luke-Kisah. 
penting tentang persembahan Roh Kudus oleh Lukas selama pelayanan adalah hubungannya yang erat dengan doa-doa Yesus." ${ }^{28}$ Lukas membuat ini lebih eksplisit dengan memasukkan Roh Kudus ke dalam Lukas 11:13 untuk membaca, "Jika bapa yang jahat saja... ketahuilah bagaimana memberikan pemberian yang baik kepada anak-anakmu, apalagi Bapamu yang di surga akan memberikan Roh Kudus kepada mereka yang meminta kepada-Nya!” Pernyataan Paulus tentang Roh yang bersyafaat bagi kita (Rm. 8:26) sangat luar biasa. Lukas, bagaimanapun, bahkan lebih baik. Melalui doa, kita dapat menerima karunia Roh Kudus (lih. Luk 3:21; Kis $1: 14 ; 4: 31 ; 8: 15)$.

\section{Karunia Roh Kudus dalam Perspektif Lukas}

Lukas tidak banyak membahas mengenai karunia Roh Kudus (charisma) yang diberikan bagi tubuh Kristus. Pembahasan mengenai karunia Roh Kudus lebih banyak dibahas dalam tulisan-tulisan Paulus. Paulus mengarahkan karunia yang diterima oleh jemaat untuk kesatuaan dan pertumbuhan tubuh Kristus. Meskipun menurut Fee kata "charismata" dipakai sekitar 50 kali untuk merujuk kepada berbagai cara kasih karunia Allah yang telah dibuktikan di antara umat-Nya. Hal ini mencakup karunia-karunia beragam termasuk hidup kekal (Rm. 6:23; 5:15), hak-hak istimewa khusus yang diberikan kepada Israel (Rm. 11:29), selibat dan perkawinan (1 Kor. 7:7), pembebasan dari bahaya kematian (2 Kor. $1: 10){ }^{29}$ Charismata juga digunakan dalam arti lebih terbatas untuk merujuk pada menifestasimanifestasi Roh. Karunia Roh merupakan pemberian atau anugerah ilahi dan menjadi manifestasi anugerah Allah dalam kehidupan umat-Nya. Berkaitan dengan karunia ilahi (charismata), terdapat term yang berbeda dengan karunia-karunia Roh (Pneumatica). Secara harafiah istilah ini diartikan "hal-hal rohani."

${ }^{28}$ George Montague, The Holy Spirit: Growth of a Biblical Tradition (New York: Paulist Press, 2006).

${ }^{29}$ Johny Sumarauw and Made Astika, "Analisis Pendayagunaan Karunia-Karunia Roh Terhadap Pertumbuhan Jemaat Gereja Pantekosta Di Indonesia ElShaddai Makassar," Jurnal Jaffray 13, no. 1 (2015): 55-76.
Namun sebenarnya kedua istilah ini dapat dipertukarkan penggunaannya dalam Alkitab. ${ }^{30}$

Merujuk kepada "Karunia Roh" yang dijanjikan sebelumnya kepada orang percaya (Kis. 1:4-5), Petrus secara eksplisit mengatakan bahwa "janji" ini tidak hanya bagi para pendengarnya yang bertobat dan percaya kepada Kristus, melainkan juga bagi keturunan mereka dan "bagi orang yang masih jauh," semua yang dipanggil Tuhan (Kis. 2:38-39). Mungkin tanpa sadar pada titik ini, Petrus menggunakan bahasa Kitab Suci: "orang yang masih jauh" mewakili yang belum tercakup oleh "semua manusia" dalam kalimat Yoel, orang-orang bukan Yahudi (Yes. 57:19; Ef. 2:17). Petrus juga mengutip, "barangsiapa yang berseru kepada nama Tuhan akan diselamatkan,” dari Yoel 2:32 (Kis. 2:21). Petrus melanjutkan khotbahnya dengan menjelaskan bahwa panggilan ini adalah untuk berseru secara khusus kepada nama Yesus (Kis. $2: 25$, 34-36), kemudian ia menyelesaikan kalimatnya dengan mengutip Yoel 2:32 "sebanyak yang akan dipanggil oleh Tuhan (Kis. 2:39). Karunia Roh Kudus adalah milik semua orang yang berbalik dari dosa dan menerima Yesus Kristus sebagai Tuhan. Kisah Para Rasul mengasumsikan bahwa karunia yang diberikan pada hari pentakosta tetap berlaku.

Lebih lanjut, kutipan pembukaan Petrus dari Nubuat Yoel mengindikasikan bahwa karunia itu harus tetap ada sekarang. Petrus menafsirkan nubuat Yoel dengan tepat sebagai "hari-hari terakhir" (2:17), memahami konteks Yoel (Yl. 3:1) dan nabi-nabi lain (sebagai contoh, Yes. 44:3) bahwa Allah akan mencurahkan Roh-Nya pada akhir zaman. "Hari-hari terakhir" adalah istilah Alkitab untuk masa itu (Yes. 2:2; Mikha 4:1). Pencurahan Roh Kudus menandai bahwa Kristus telah duduk di sebelah kanan Allah Bapa (Mzm.110:1; Kis. 2:33-35) dan pemerintahanNya telah dimulai.

Lebih terus terang lagi, struktur argumentasi Petrus sendiri mengharuskan karunia ini masih ada hingga saat ini bersamaan dengan diselamatkannya orang-orang melalui percaya kepada Kristus. Ketika orang-orang asing

${ }^{30}$ French L Arrington, Pentecostal Perspective Christian Doctrine [Doktrin Kristen Perspektif Pentakosta], ed. Gernaida Krisna Pakpahan (Yogyakarta: ANDI, 2015). 
terheran-heran mendengar para murid berbicara dalam bahasa-bahasa lain oleh inspirasi Roh Kudus, Petrus mengatakan bahwa hal itu menggenapi nubuat Yoel mengenai pencurahan Roh Kudus pada hari-hari terakhir. Dengan demikian, Petrus berargumentasi bahwa seluruh nubuat juga sedang terjadi: barangsiapa berseru kepada kepada nama Tuhan akan diselamatkan (Kis. 2:21). Keselamatan dan karunia Roh Kudus terjadi pada masa yang sama; mereka yang menerima Kristus menerima karunia pada saat pertobatan.

Tentu saja tidak semua aspek Pentakosta normatif bagi semua pada zaman ini. Beberapa aspek dari Pentakosta pertama-seperti angin dan api-tidak berulang setelah Kisah Para Rasul 2. Namun meski beberapa narasi dalam Kisah Para Rasul memang memungkinkan perdebatan mengenai seberapa sering bahasa lidah menyertai pencurahan Roh Kudus, dalam praktiknya, bahasa lidah (bersama nubuat) jelas menandai penerimaan pemberdayaan nubuat dari Roh Kudus (kemampuan untuk berbicara bagi Allah) dalam Kis. 2:4; 10:44-47; dan 19:6). Faktanya, ketika Petrus mendengar orang-orang non Yahudi berbicara dalam bahasa lidah, ia terheran-heran karena mereka "menerima Roh Kudus sama seperti kita” (Kis 10:47).

Kisah Para Rasul memberikan pola yang menunjukkan bahwa fenomena nubuat itu setidaknya sering menyertai pemberian Roh Kudus dalam pengertian yang ditekankan Lukas tanpa pernah mengindikasikan bahwa pola ini seharusnya berubah. Karena (1) karunia itu permanen (Kis 2:39), (2) Lukas tiga kali menggunakan bahasa lidah untuk meneguhkan penerimaan karunia, (3) ia menggambarkan respons ini sebagai fenomena yang diinspirasikan Roh Kudus bukan hasil kebudayaan manusia (Kis 2:4), dan (4) ia tidak mengimplikasikan bahwa fenomena ini akan berakhir, beban pembuktian yang berat jatuh dipundak siapapun yang berargumen bahwa bahasa lidah telah berakhir pada masa kini.

Demikian juga karya Roh Kudus yang berlangung dalam Kisah Para Rasul tidak terbatas pada bahasa lidah. Kisah Para Rasul menekankan pelayanan mukjizat yang dipraktikkan oleh para rasul pertama (Kis. 5:12), para rasul kemudian (14:3), dan para saksi lain yang diberdayakan oleh Roh Kudus (Kis. 6:8). Seperti dikemukakan sebelumnya dalam Kisah Para Rasul tanda-tanda dan keajaiban tetap menjadi metode utama untuk menarik perhatian orang kepada injil.

Dalam Kisah Para Rasul, narasi Lukas mencatat bahwa Roh Allah memberdayakan gereja-Nya untuk menginjili dunia, baik melalui tanda-tanda atau keberanian berbicara atau keduanya. Namun kita harus memerhatikan bahwa dalam masa kesulitan mereka, umat Kristen mula-mula meminta pemberdayaan bagi mukjizat-mukjizat penginjilan melalui doa (4:2931).

Karunia Roh Kudus diarahkan kepada gereja sebagai tubuh Kristus. Karunia Roh dilimpahkan hanya di dalam dan untuk tubuh Kristus. Ini bukan pilihan, melainkan mutlak harus ada dalam peribadatan. Karunia ini dimiliki oleh umat Allah yang ditujukan untuk pembangunan gereja (1Kor. 12:7), yaitu melayani tubuh Kristus dan segala keperluannya. Karunia Roh Kudus menyajikan kesejahteraan gereja komunitas untuk saling mendukung sebagai tubuh Kristus. Lalu bagaimana dengan realitas karunia Roh pada masa kini? Gereja-gereja berlomba-lomba untuk melakukan test karunia bagi para pelayananya dengan maksud agar pelayanan yang kelak dimasuki atau digeluti sesuai dengan karunia yang Tuhan berikan. Dengan melayani sesuai karunia maka pelayanan akan maksimal.

Peneliti sama sekali tidak menemukan bagaimana karunia Roh dalam tulisan Lukas. Karunia Roh banyak dibahas dalam tulisantulisan Paulus. Karunia-karunia yang dicantumkan dalam dua bagian Alkitab yaitu 1 Korintus 12:8-10 dan Efesus 4:11 terkait dengan bentuk-bentuk karunia-karunia rohani yang tidak dipunyai orang-orang Kristen sejak lahir. Karunia-karunia dalam kedua bagian ini mungkin hanya beberapa contoh, namun yang tercantum di sana memberikan kesempatan untuk menggali beberapa karunia dengan lebih rinci. Dalam beberapa kasus, pandanganpandangan populer tentang apa yang termasuk karunia-karunia tersebut hanya didasarkan pada tradisi "karismatik", walaupun dalam kasus-kasus 
lain pemahaman yang populer mungkin hampir sama dengan apa yang Paulus maksudkan.

Berikut peneliti memberikan beberapa alasan yang mendukungnya. Pertama, Lukas mencatat pemberdayaan gereja pada hari Pentakosta sebagai pengalaman normatif umat Kristen. Seperti kita lihat di atas, pengalaman ini mencakup pemberdayaan untuk berbicara dengan inspirasi Roh Kudus, khususnya untuk bersaksi, dan dalam Kisah Para Rasul setidaknya mencakup kalimat-kalimat yang "diinspirasikan" seperti nubuat dan bahasa lidah. Kedua, para penulis Injil mencatat pelayanan mukjizat Yesus sebagai model bagi para murid. Tentu ini tidak berimplikasi bahwa semua dari kita seharusnya sama ahlinya dalam semua karunia seperti yang ditekankan Paulus. Namun, ini berimplikasi bahwa gereja melalui anggota-anggotanya seharusnya melakukannya. Ketiga, surat Paulus mengenai karunia tidak terlepas dari pandangannya mengenai gereja. Paulus percaya setiap anggota tubuh Kristus memiliki fungsi khusus dan seharusnya meyumbangkan karunianya untuk memperkuat gereja. Paulus tidak melihat satupun fungsi-fungsi khusus tubuh tersebut seharusnya tidak ada lagi sebelum kedatangan Tuhan kembali. Bahkan ia secara eksplisit menyatakan bahwa karunia-karunia kita yang tidak sempurna akan berakhir hanya pada saat itu (1 Kor. 13:8-13).

\section{KESIMPULAN}

Karya Roh dalam Lukas-Kisah Para Rasul mengungkapkan era baru dan memperlengkapi komunitas baru dengan kemampuan untuk bersaksi. Hasilnya, para pemimpinnya berani dan bijaksana dalam memberikan kesaksian. Roh Kudus juga mengungkapkan apa yang harus dilakukan gereja dalam misi dan ke mana seseorang harus pergi. Sebelum datang ke komunitas orang percaya, Roh adalah kuasa pengurapan yang terikat pada Yesus dalam kelahiran dan pelayanan. Ia juga merupakan sumber inspirasi bagi tulisan-tulisan Kitab Suci. Teks kunci Lukas 3:16 dan banyak singgungan berikutnya menunjukkan bahwa perlengkapan ini adalah bagian dari apa yang Lukas lihat bukan hanya sebagai bukti dari era baru tetapi kehadiran kehidupan yang diselamatkan. Kedatangan Roh mencerminkan hasil dari janji Bapa dan memungkinkan kehidupan untuk dijalani sebagai hasil dari pekerjaan penyucian Allah melalui Yesus (Kis. 11:9, 18). Namun, inti dari semua pekerjaan Roh Kudus dalam narasi Lukas-Kisah Para rasul bukanlah kuasa untuk melakukan mukjizat-mukjizat, namun hati yang diubahkan yang belajar bagaimana mengasihi, dan poin ini sangat relevan bagi gereja sepanjang abad

\section{KEPUSTAKAAN}

Andriati, Sarah. "Pemahaman Tentang Karunia Roh Kudus Dalam Pemberdayaan Kualitas Guru Pendidikan Agama Kristen.” Jurnal Antusias 4, no. 7 (2018): 34-61.

Arrington, French L. Pentecostal Perspective Christian Doctrine [Doktrin Kristen Perspektif Pentakosta]. Edited by Gernaida Krisna Pakpahan. Yogyakarta: ANDI, 2015.

Baumgärtel, Friedrich. Theological Dictionary of the New Testament. Edited by Gerhard Kittel, Gerhard Friedrich, and Geoffrey Bromily. Grand Rapids, MI: Eerdmans, 2012.

Bovon, François. Luke the Theologian: Fifty-Five Years of Research (1950-2005). Waco, Tex: Baylor University Press, 2007.

Bratcher, Nicholas, and Nicholas Bratcher. "Understanding the Mystery: Weighing Cessationist and Continuationist Debate of Prophecy in the Pauline Epistles By." Western Kentucky University, 2014.

Bruce, F. F. "The Holy Spirit in the Acts of the Apostles." Interpretation: A Journal of Bible and Theology 27, no. 2 (1973): 166-83. https://doi.org/https://doi.org/10.1177\% 2F002096437302700203.

Drewes, B.F. Tafsiran Alkitab: Kisah Para Rasul. Jakarta: BPK Gunung Mulia, 2014.

Fitch, Alger. ACTS: What a Doctor Found When He Examined Christ's Body. 2nd ed. Surabaya: YAKIN, 2011.

Green, Michael. Evangelism in the Early Church. Revised. Grand Rapids: Eerdmans Publishing Co - A, 2004. 
Gunkel, Hermann. The Influence of the Holy Spirit. Edited by Tr. Roy A. Harrisville and Philip A Quanbeck. Philadelphia: Fortress Press, 1979.

Jervell, Jacob. The Theology of the Acts of the Apostles (New Testament Theology). Cambridge, MA: Cambridge University Press, 2007.

Macchia, Frank D. "Baptism in the Holy Spiritand-Fire: Luke's Implicitly Pneumatological Theory of Atonement." Religions 9, no. 2 (2018). https://doi.org/10.3390/rel90200 63.

Marshal, L. Howarld. Luke: Historian and Theologian. Grand Rapids, MI: Zondervan Publishing, 1998.

Marshall, I Howard. Luke: Historian and Theologian. Downers Grove: InterVarsity Press, 1998.

Martin, Ralph P. New Testament Foundations: A Guide for Christian Students. Grand Rapids: Eerdmans, 2016.

Mayne, John. "Pneumatology in Lukes Gospel." Malyon College, 2013.

Montague, George. The Holy Spirit: Growth of a Biblical Tradition. New York: Paulist Press, 2006.

Moore, Mark. "Luke's View of the Holy Spirit." Enrichment Journal, 2018.

Reflection, Christian. "The Holy Spirit's Gift and Witness." Pentecost, 2015.

Sheldon, James. Mighty in Word $\mathcal{E}$ Deed: The Role of the Holy Spirit in Luke-Acts. Peabody, Massachusetts: Hendrickson Publishers, Inc, 2000.

Stronstad, Roger. The Charismatic Theology of St. Luke: Trajectories from the Old Testament to Luke-Acts. 2nd ed. Grand Rapids: Baker Publishing, 2012.

Sumarauw, Johny, and Made Astika. "Analisis Pendayagunaan Karunia-Karunia Roh Terhadap Pertumbuhan Jemaat Gereja Pantekosta Di Indonesia El-Shaddai Makassar.” Jurnal Jaffray 13, no. 1 (2015): $55-76$.

Talumewo, Steven H. Sejarah Gerakan Pentakosta. Yogyakarta: ANDI Offised, 2008.

Wenham, G. J., J. A. Motyer, D.A Carson, and
R.T France. New Bible Commentary. Downers Grove, IL: InterVarsity Press, 1994. 